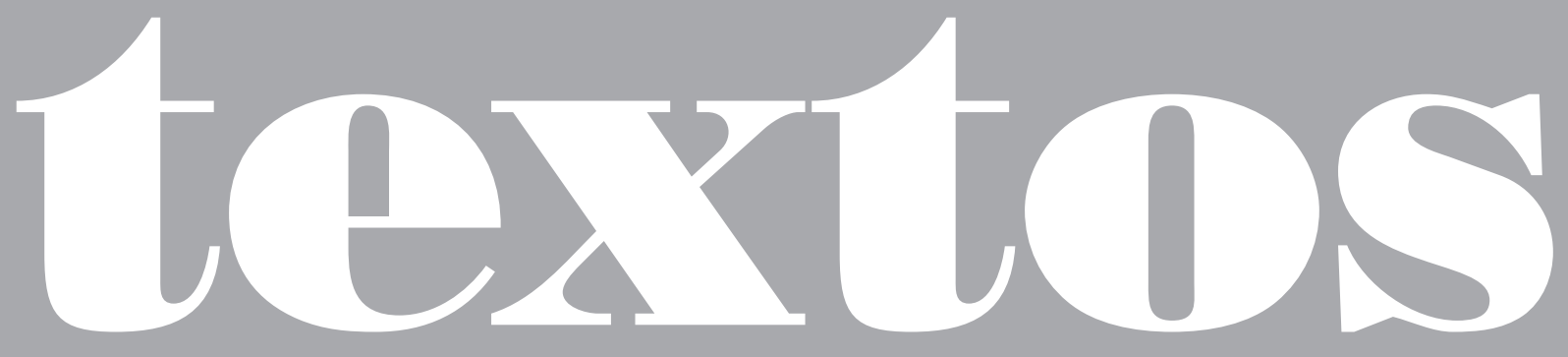





\section{A propósito de um equívoco da literatura}

\section{Varlam Chalámov}

Tradução do original russo, apresentação e notas de Francisco Araújo*

\section{LITERATURA E BARBÁRIE DO SÉCULO XX}

Como autor da literatura de testemunho do século XX, Varlam Tikhonovitch Chalámov (1907-1982) coloca-se ao lado de Jorge Semprún, Imre Kertész, Primo Levi - vítimas dos campos de concentração nazistas - e de seu compatriota Aleksandr Soljenítsin.

Filho de um sacerdote da Igreja Ortodoxa, nasceu em Vologda. Quando era estudante de direito da Universidade de Moscou engajou-se na oposição a Stalin. Foi detido como "elemento socialmente perigoso", em 1929, por difundir cópias do "Testamento de Lênin" - carta aos membros do Comitê Central do Partido Comunista, onde alertava sobre as inclinações monopolizadores de Stalin.

Pelo exercício de "atividades trotskistas contrarrevolucionárias" é detido pela segunda vez, em 1937. Então passaria longo período nos campos de trabalho de Kolimá (Sibéria), ao todo, 20 anos. Em 1954 começa a escrever os contos e ensaios que comporiam sua epopeia de seis volumes. Esta só viria a ser publicada na URSS em 1989, sete anos após sua morte.

* Francisco Araújo é tradutor e mestrando do curso de Literatura e Cultura Russa na FFLCH/USP. 
Chalámov pretende que sua prosa seja alheia a qualquer mentira. Diante do horror que revela a insuficiência da língua e abala a fé no homem, a única forma que encontra de manter no horizonte os ideais do humanismo ante a barbárie racionalizada - a violência de Estado - é a ideia de oferecer um testemunho. Para ele, o narrador honesto deve conhecer com perfeição o material que transforma em arte. Impõe-se ao escritor o desafio de engendrar a forma de melhor narrar o horror a quem não o conhece. Para Boris Schnaiderman, seus contos "são o polo extremo atingido pela assim chamada 'literatura do Gulag'".

A obra de Chalámov tem despertado interesse da crítica literária e inspirado autores contemporâneos. Este primeiro dos Ensaios sobre o Mundo do Crime, o quarto entre os seis volumes ordenados pelo autor, trata da recusa às literaturas humanísticas, sobretudo do século XIX, e à picaresca russa do início do século XX. Dos escritores dessa literatura, segundo Chalámov, uns não dizem a verdade sobre o mundo do crime, outros Ihe conferem uma aura romântica. Uma voz necessária, a nos lembrar da barbárie cotidiana que a todos envolve.

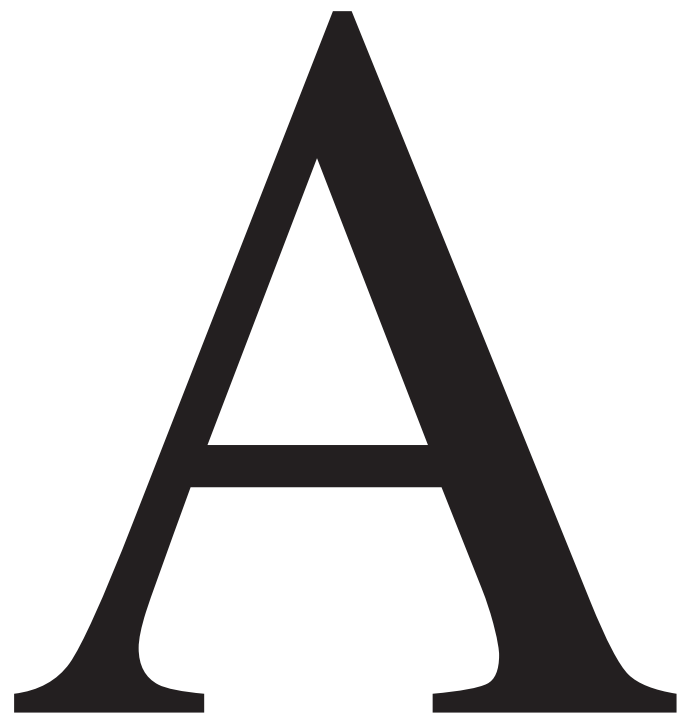

literatura de ficção sempre representou o mundo dos criminosos com simpatia, por vezes com complacência. Seduzida por seu esplendor aparente, ela o envolveu de uma aura romântica. Os artistas não foram capazes de discernir a verdadeira e repugnante face desse mundo. É um pecado pedagógico, um erro pelo qual nossa juventude paga muito caro. Pode-se até compreender que um rapaz de 14 ou 15 anos se deixe fascinar pelas heroicas figuras desse universo; mas a um artista é imperdoável. Entretanto, mesmo entre os grandes escritores não encontramos um que, discernindo a verdadeira face do ladrão, tenha lhe voltado as costas ou tenha-o reprovado, como deve todo grande artista reprovar tudo o que é moralmente inadmissível. Por capricho da história, os mais expansivos propagadores da consciência e da honra, como Victor Hugo, por exemplo, consagraram grandes esforços ao louvor do mundo do crime. A Hugo parecia que o mundo do crime é aquela parte da sociedade que protesta abertamente, com firmeza e decisão, contra a hipocrisia do mundo dominante. Mas ele não se deu ao trabalho de examinar de que posição essa comunidade de malfeitores luta contra qualquer poder governamental. Não são poucos os rapazes 
que, depois da leitura do romance de Hugo, buscam conhecer "miseráveis" reais. O apelido Jean Valjean existe até hoje entre os bandidos.

Em suas Recordações da Casa dos Mortos Dostoiévski evita dar uma resposta clara e direta a essa questão. Do ponto de vista do verdadeiro mundo do crime - dos autênticos blatares $^{1}$ - todos esses Petrov, Lutchka, Suchilov, Gazin² são uns "patos", otários, broncos, isto é, fráieres ${ }^{3}$, são aqueles que a bandidagem despreza, espolia e pisoteia. Para os blatares, os assassinos e ladrões Petrov e Suchilov estão muito mais próximos do autor de Recordações da Casa dos Mortos que da bandidagem. Os "ladrões" de Dostoiévski eram alvo de ataque e roubo do mesmo modo que Aleksandr Petrovitch Goriantchikov $^{4}$ e seus pares, por maior que fosse o abismo que separava os delinquentes da nobreza daqueles que provêm da gente simples. É difícil dizer por que Dostoiévski não se decidiu por construir uma imagem verídica dos bandidos. Um bandido não é simplesmente aquele que rouba. É possível roubar, e até mesmo de modo sistemático, mas não ser um blatar, ou seja, não pertencer a essa abominável ordem clandestina que a bandidagem representa. Ao que parece, na colônia penal em que Dostoiévski esteve preso não havia essa "categoria". Normalmente, tipos como esse não são condenados a penas de prazo muito longo, pois não é de assassinos que se constitui sua grande maioria. Ou melhor, não se constituía no tempo de Dostoiévski. Blatares condenados por atos "banhados de sangue", aqueles criminosos de mão "ousada", não eram especialmente numerosos no mundo do crime. Arrombadores, assaltantes, golpistas, batedores de carteira - eis

1 De blatar: bandido ou criminoso profissional que segue o "código de conduta" da bandidagem. (N. do T.)

2 Personagens de Recordações da Casa dos Mortos (186162), de Dostoiévski, romance baseado na experiência do escritor, que estivera detido por quatro anos numa colônia penal siberiana. (N. do T.)

3 De fráier: termo do jargão criminal. Indica o criminoso ocasional, que não faz parte da bandidagem; sinônimo de ingênuo, vítima dos bandidos de verdade. (N. do T.)

4 Personagem condenado pelo assassinato da esposa, do qual as memórias, lidas por um narrador, constituem o enredo, conduzido em primeira pessoa, de Recordações da Casa dos Mortos. (N. do T.) as principais categorias da sociedade dos urkas, ou urkaganes $^{5}$, como se autodenominam os criminosos. A expressão "mundo do crime" é um termo com significado preciso. Vigarista, meliante, urka, urkagán, blatar - são todos sinônimos. Dostoiévski não os encontrou em sua prisão, se os tivesse encontrado, teríamos sido privados, talvez, das páginas mais nobres de seu romance, aquelas que afirmam a fé no homem, na existência de um princípio positivo na natureza humana. Mas Dostoiévski não encontrou verdadeiros blatares. Os personagens encarcerados de Recordações da Casa dos Mortos são pessoas tão ocasionais no crime quanto o próprio Aleksandr Petrovitch Goriantchikov. O roubo, por exemplo, de um pelo outro - o que Dostoiévski especialmente ressalta, detendo-se nisso por muitas vezes - acaso seria coisa possível no mundo dos blatares? O que por lá se encontra é a espoliação dos fráieres, a repartição desse espólio, o jogo de cartas e a passagem das coisas roubadas de um bandido a outro, a depender da vitória nas partidas de faraó ou trinta e um. Na Casa dos Mortos Gazin vende aguardente, o que também fazem outros taberneiros. Mas os blatares não esperariam muito para extorquir a bebida de Gazin, de modo que não teria tempo de fazer carreira.

De acordo com a antiga "lei" da bandidagem, um blatar não deve trabalhar no lugar em que está preso, seu trabalho deve ser feito por fráieres. No mundo do crime, esses Miasnikov e Varlamov receberiam o desdenhoso apelido de "carregadores do Volga". Todos esses "ossos" (soldados), Bakluchin, maridos de Akulka ${ }^{6}$, nada têm a ver com o mundo dos criminosos profissionais, o mundo da bandidagem. São simplesmente homens que vieram a se deparar, por algum acaso, com a força negativa da lei, que às cegas ultrapassaram algum limite, como Akim Akimovitch - um típico fraieriuga ${ }^{7}$. Quanto ao mundo blatar, é um ambiente que tem sua lei e que mantém eterna guerra com

5 De urka, urkagán: bandido proeminente no mundo do crime; de modo geral equivale ao termo blatar. (N. do T.)

6 Estes últimos, citados em sequência, são outros personagens de Recordações da Casa dos Mortos; "o marido de Akulka", em particular, é personagem-título de um dos capítulos. (N. do T.)

7 Variação diminutiva de fráier. (N. do T.) 


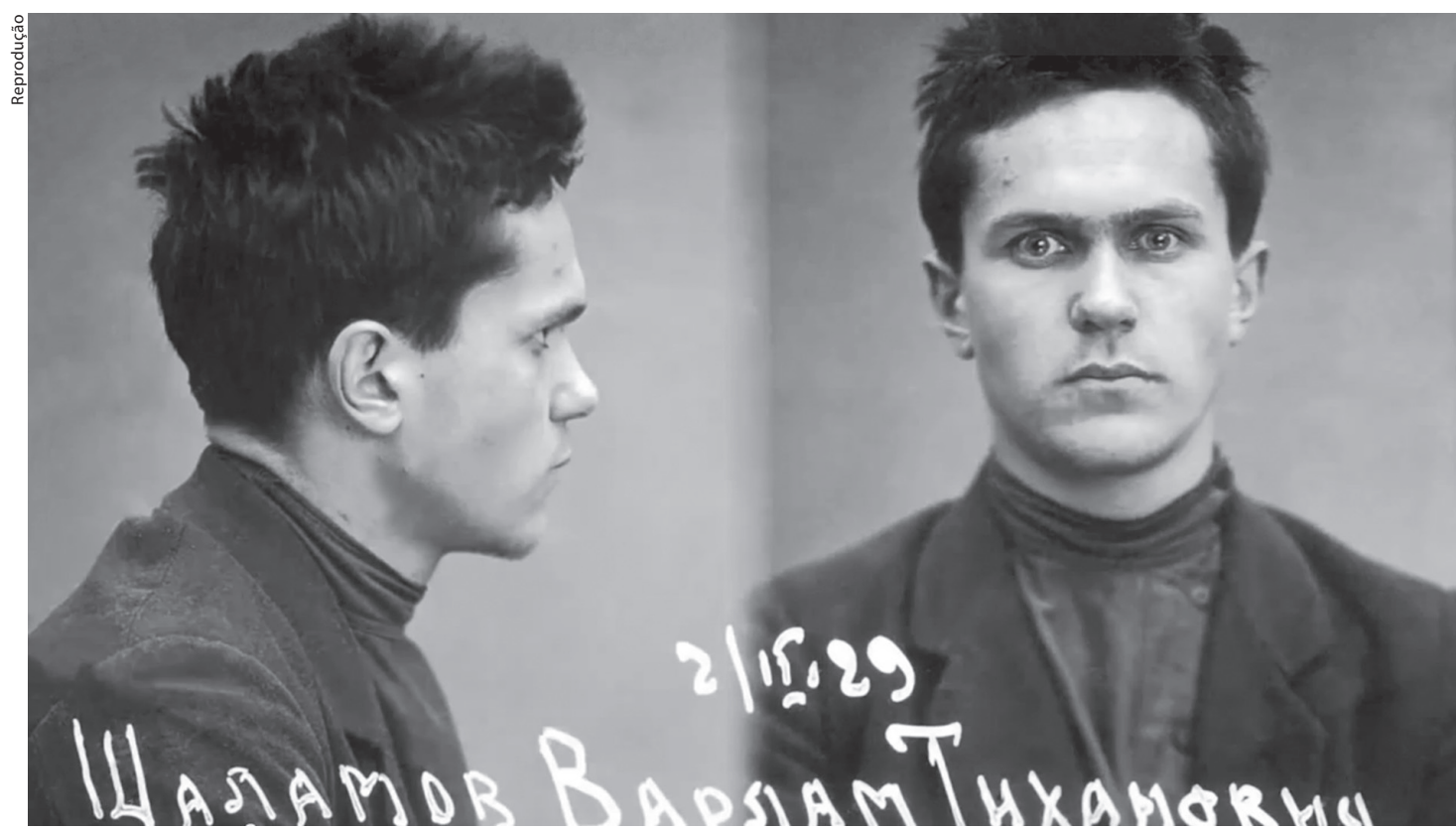

Varlam Chalámov em foto de 1929, quando de sua primeira prisão, em Vishera

esse outro mundo do qual são representantes tanto Akim Akimovitch quanto Petrov, com o major “oito-olhos". O major é até mais próximo aos blatares. É uma autoridade comissionada por Deus, então lidar com ele, enquanto representante do poder, é um tanto mais simples, e a um major desses qualquer blatar teria muitas coisas belas a dizer sobre justiça, honra e outras elevadas matérias. Ludíbrio que há séculos se repete. $\mathrm{O}$ ingênuo major de rosto espinhento é deles um inimigo declarado, enquanto tipos como Akim Akimovitch e Petrov são suas vítimas.

Em nenhum dos romances de Dostoiévski os bandidos estão de fato representados. Dostoiévski não os conhecia, e se os viu e conheceu, como artista voltou-lhes as costas.

Em Tolstói não há nenhum retrato significativo de homens desse tipo, nem mesmo em Ressurreição, onde os traços externos e ilustrativos estão postos de tal maneira que o artista se exime de responder por eles.

Um escritor que se deparou com esse universo foi Tchekhov. Durante sua viagem a Sacalina ${ }^{8}$

8 Ilha do extremo oriente da Rússia, onde situava-se a maior colônia penal do império czarista. Em 1890 Anton Tchekhov empreende uma viagem para Sacalina a fim de estudar a vida dos condenados aos trabalhos forçados; houve alguma coisa que alterou sua escrita. Em algumas das cartas posteriores ao seu retorno, Tchekhov expressa claramente que tudo o que escreveu antes dessa viagem lhe parecia futilidade, qualquer coisa indigna de um escritor russo. Como em Recordações da Casa dos Mortos, também na ilha de Sacalina a estupidificante e depravadora torpeza dos lugares de detenção arruína, e não poderia deixar de arruinar, tudo o que há de puro, de bom, de humano. O mundo dos blatares amedronta o escritor. Tchekhov percebeu nele o principal acumulador dessa torpeza, uma espécie de reator nuclear a se abastecer do combustível que ele mesmo produz. Mas Tchekhov não podia mais que abrir os braços, sorrir tristonho e apontar esse mundo com um gesto doce, mas insistente. Também ele o conheceu por Hugo. Tchekhov esteve por bem pouco tempo em Sacalina e até sua morte não ousou utilizar esse material em sua obra de ficção.

Era de se esperar que o lado biográfico da criação de Gorki lhe desse motivos para apresentar os blatares de maneira crítica e veraz.

em 1895 publica o volume A Ilha de Sacalina - De Notas de Viagem - , do qual a maior parte fora publicada entre 1893-94 na revista político-literária moscovita Russkaia mysl' (Pensamento Russo). (N. do T.) 


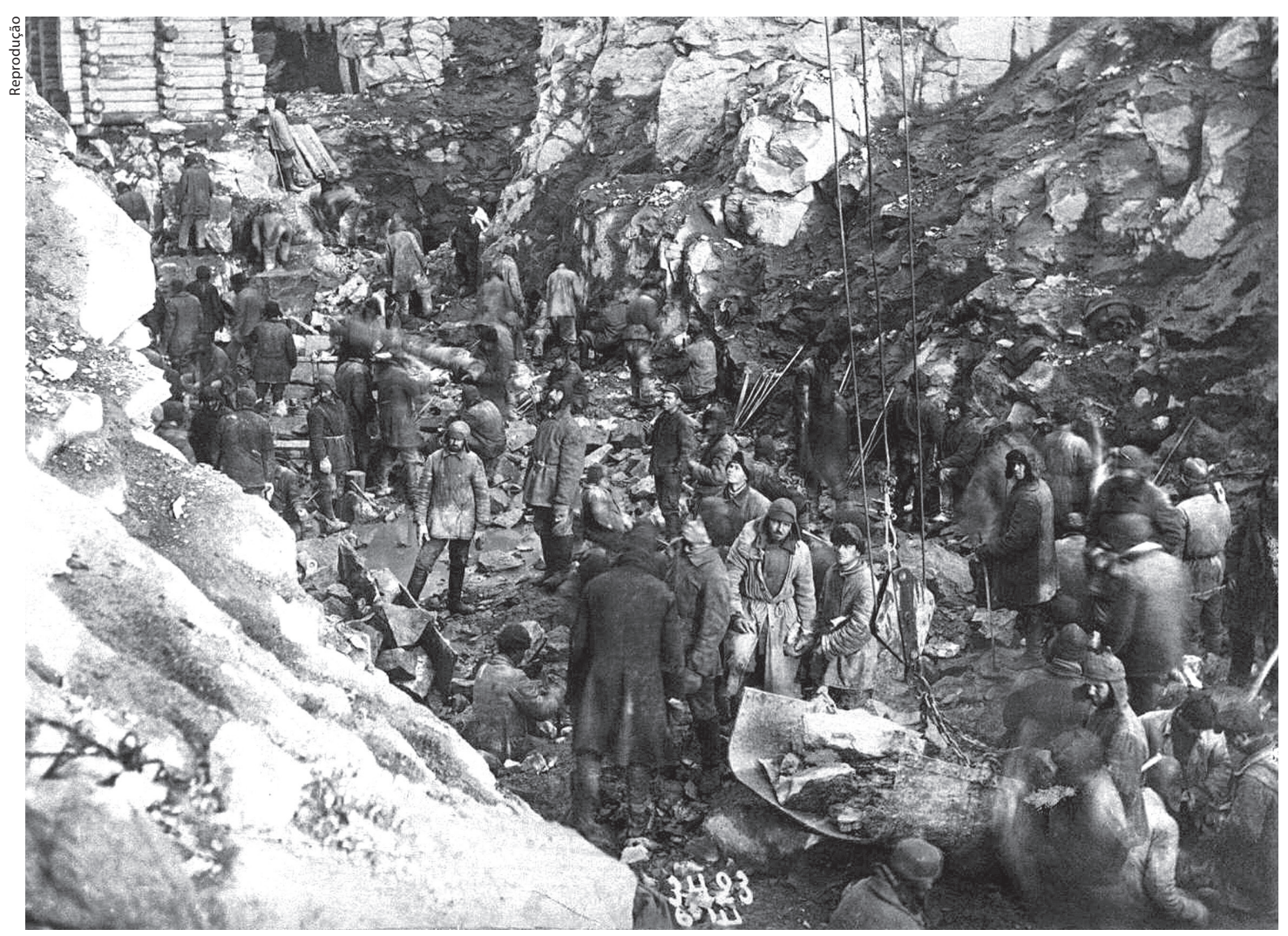

O Gulag de Kolimá, no qual Chalámov passou boa parte da vida

Tchelkach ${ }^{9}$ é incontestavelmente um blatar. Mas no conto esse ladrão reincidente é representado como os personagens de Os Miseráveis, a partir daquele mesmo rigor forçado e enganoso. A Gavrila, é claro, é possível interpretar não apenas como um símbolo da alma camponesa. Ele é discípulo do urkagan Tchelkach. Um aprendiz fortuito, certamente, mas indispensável. Um discípulo que amanhã, talvez, como um chtimp ${ }^{10}$ corrompido, subirá o primeiro degrau da escada que conduz ao mundo do crime. Porque, como disse um filósofo blatar, "não se nasce bandido, bandido se torna". Em Tchelka$c h$, Gorki, que havia se deparado com o mundo da bandidagem na juventude, contentou-se com apenas demonstrar um entusiasmo irrefletido diante da aparente liberdade de julgamento e ousadia de conduta desse grupo social.

9 Protagonista do conto homônimo de Maksim Gorki (1868-1936). (N. do T.)

10 Termo semelhante a fráier; criminoso novato, inexperiente. (N. do T.)
Vaska Pepe ${ }^{11}$ (Ralé) é um bandido inteiramente dúbio. Do mesmo modo que Tchelkach, ele é romantizado, exaltado e em nada reprovado. A autenticidade de certos traços exteriores dessa figura e a manifesta simpatia do autor fazem com que também Vaska Pepel se preste a uma causa negativa.

Tais são as tentativas de representar o mundo do crime empreendidas por Gorki. Ele também não conhecia esse mundo, pelo visto não se deparou com blatares de verdade, porque isso é geralmente difícil a um escritor. O mundo da bandidagem é fechado, apesar de não ser uma ordem estritamente conspiratória e clandestina, não permitem que estranhos a estudem ou observem. Nenhum blatar se abriria, como faria a um igual, nem com o Gorki-vagabundo, nem com o Gorki-escritor, porque para qualquer blatar Gorki seria antes de tudo um fráier.

11 Personagem da peça Ralé (1901-02), de Maksim Gorki; Vaska Pepel é um ladrão nascido na cadeia. (N. do T.) 
Nos anos 20 nossa literatura foi tomada por uma moda de salteadores. Bienia Krik, de Bábel, O Ladrão, de Leónov, Motke Malkhamoves, de Selvinski, Vaska Svist em Apuros, de V. Inber, O Fim de uma Gangue, de Kaverin e, por fim, o vigarista Ostap Bender, de Ilf e Petrov $^{12}$ - ao que parece, todos os escritores pagaram frívolo tributo a essa repentina demanda do romantismo criminal. A poetização desenfreada dos delinquentes fez-se passar por "nova corrente" literária e seduziu muitas penas experientes da literatura. Apesar do extraordinariamente débil entendimento que demonstram autores de obras com semelhante tema, tanto os citados quanto os não citados, em relação à matéria que pensavam revelar, não deixaram de obter êxito junto aos leitores e, consequentemente, causaram danos consideráveis.

Posteriormente foi ainda pior. Teve vez um longo período de entusiasmo pela famigerada $p e$ rekóvka" $a^{13}$, aquela tal "reforja" da qual os bandidos caçoavam e até hoje não se cansaram de caçoar. Foram criadas as comunas de Bolshevo e Liubertsi, 120 escritores redigiram um trabalho "coletivo" sobre o Bielomorkanal ${ }^{14}$, que resultou num livro publicado em exemplar extraordinariamente pare- cido com o Evangelho ilustrado. O apogeu literário desse período foi Aristocratas, de Pogódin ${ }^{15}$, em que o dramaturgo repete pela milésima vez o velho equívoco, sem dar-se ao trabalho de pensar de modo mais sério naquelas pessoas reais que representavam em vida, diante de seus ingênuos olhos, um espetáculo de fácil compreensão.

Foram lançados muitos livros e filmes, muitas peças foram montadas sob o tema da reabilitação de criminosos. Uma lástima!

O mundo do crime permanece, desde os tempos de Gutenberg até nossos dias, um livro fechado a sete selos, tanto para autores quanto para leitores. Os escritores que abordaram esse seriíssimo tema trataram-no levianamente, deixando-se seduzir e iludir pelo fosforescente brilho da criminalidade, adornando sua verdadeira face com uma máscara romântica, com o que reforçam, junto ao leitor, uma ideia inteiramente falsa desse pérfido e repugnante universo, no qual nada de humano está contido.

A agitação em torno das diversas "reforjas" acabou por dar uma trégua que salvou a muitos milhares de ladrões profissionais.

Mas o que afinal é o mundo do crime?
12 Biénia Kriké protagonista da série de contos intitulada Os Contos de Odessa (1931) e da peça O Pôr do Sol (1927), de Isaak Bábel (1894-1940); O Ladrão (1927), romance de Leonid Leonov (1899-1994), conta a história de um ex-herói da guerra civil, comandante do Exército Vermelho, que se torna um ladrão no período da NEP: Moltke Malkhamoves (1923), poema escrito no "dialeto" de Odessa, de Iliá Selvinski (1899-1968); Vaska Svist em Apuros, poema de Vera Inber (1890-1972); O Fim de uma Gangue (1925), romance de Veniamin Kaverin (1902-89); Ostap Bender é uma espécie de malandro aventureiro, um dos mais populares personagens da literatura picaresca russo-soviética, protagonista dos romances Doze Cadeiras (1928) e Bezerro de Ouro (1931), de Iliá Ilf (1897-1937) e levguiêni Petrov (1902-42). Bender, que tinha o Rio de Janeiro como cidade dos sonhos, cunhou o bordão: "Não, isso não é o Rio de Janeiro", pronunciado por ocasião de algum enfado ou decepção. (N. do T.)
13 Literalmente: tornar a forjar; trata-se da "reeducação" dos detentos por meio do trabalho correcional e da atividade educacional promovida nos campos de trabalho soviéticos. Oriundo da metalurgia, acredita-se que o termo tenha surgido durante a construção do Bielomorkanal - canal que liga o Mar Branco ao Báltico - onde trabalharam milhares de detentos. (N. do T.)

14 Encabeçado por Maksim Gorki, um grupo de 120 escritores visitou o recém-inaugurado Bielomorkanal em agosto de 1933; 36 deles tomaram parte na elaboração de um volumoso livro dedicado à construção do canal, intitulado O Canal Mar Branco-Mar Báltico de Stalin e publicado em 1934, coincidindo propositadamente com o XVII Congresso do Partido Comunista. (N. do T.)

15 Aristocratas (1934), peça de Nikolai Pogódin (pseudônimo de Stukálov, 1900-62), sobre a reabilitação de criminosos por meio do trabalho. (N. do T.) 